\title{
Extracellular mycosynthesis of gold nanoparticles using Fusarium solani
}

\author{
K. Gopinath · A. Arumugam
}

Received: 27 December 2012/ Accepted: 6 June 2013/Published online: 3 July 2013

(c) The Author(s) 2013. This article is published with open access at Springerlink.com

\begin{abstract}
The development of eco-friendly methods for the synthesis of nanomaterial shape and size is an important area of research in the field of nanotechnology. The present investigation deals with the extracellular rapid biosynthesis of gold nanoparticles using Fusarium solani culture filtrate. The UV-vis spectra of the fungal culture filtrate medium containing gold ion showed peak at $527 \mathrm{~nm}$ corresponding to the plasmon absorbance of gold nanoparticles. FTIR spectra provide an evidence for the presence of heterocyclic compound in the culture filtrate, which increases the stability of the synthesized gold nanoparticles. The X-ray analysis respects the Bragg's law and confirmed the crystalline nature of the gold nanoparticles. AFM analysis showed the results of particle sizes $(41 \mathrm{~nm})$. Transmission electron microscopy (TEM) showed that the gold nanoparticles are spherical in shape with the size range from 20 to $50 \mathrm{~nm}$. The use of $F$. solani will offer several advantages since it is considered as a non-human pathogenic organism. The fungus $F$. solani has a fast growth rate, rapid capacity of metallic ions reduction, NPs stabilization and facile and economical biomass handling. Extracellular biosynthesis of gold nanoparticles could be highly advantageous from the point of view of synthesis in large quantities, time consumption, eco-friendly, non-toxic and easy downstream processing.
\end{abstract}

Keywords Fusarium solani - Extracellular biosynthesis . Gold nanoparticles $\cdot$ Eco-friendly $\cdot$ Bio-reduction

K. Gopinath · A. Arumugam ( $₫)$

Department of Nanoscience and Technology,

Alagappa University, Karaikudi 630 004, India

e-mail: sixmuga@yahoo.com

K. Gopinath

e-mail: gopiscientist@gmail.com

\section{Introduction}

Nanostructured materials have been attracting considerable attention because of their unique physical and chemical properties, its potential applications in many fields such as nanocomputers (Tseng and Ellenbogen 2001), catalysis (Kim et al. 2003), optical devices (Kamat 2002), cell labeling (Wu et al. 2003), cell tracking (Parak et al. 2002), in vivo imaging (Dubertret et al. 2002), DNA detection (Taylor et al. 2000), and antimicrobial activity (Krishnaraj et al. 2012). The interaction between microorganism (e.g., bacteria, yeast, fungi) and metals have been reported as bio-reducing agent of the gold nanoparticles synthesis (Gericke and Pinches 2006). An extremophilic actinomycete Thermomonospora sp. has been reported to synthesize extracellular monodispersed, spherical gold nanoparticles of average size of $8 \mathrm{~nm}$ (Ahmad et al. 2003a). Some of the common algal genus like, Anabaena, Calothrix, and Leptolyngbya cyanobacteria have also been found to produce intracellular $\mathrm{Au}, \mathrm{Ag}, \mathrm{Pd}$, and Pt nanoparticles (Brayner et al. 2007). Biosynthesis of silver, gold and bimetallic nanoparticles using the filamentous fungus Neurospora crassa (CastroLongoria et al. 2011) and bimetallic Au-core, Ag-shell nanoparticles have been synthesized using Azadirachta indica and Aloe vera leaf extract (Shankar et al. 2004; Chandra et al. 2006).

Researchers in National Chemical Laboratory (NCL) Pune, India, have investigated that the eukaryotic organisms such as fungi can be used to prepare nanoparticles and also 200 genus of fungi were investigated for this purpose. From this extensive screening study, two genera of fungi, Verticillium sp. (Mukherjee et al. 2001a, b) and Fusarium oxysporum, were found to produce nanoparticles. The latter displayed the ability to 
synthesize silver, gold and platinum nanoparticles extracellularly (Mukherjee et al. 2002; Ahmad et al. 2003b; Duran et al. 2005; Syed and Ahmad 2012). Pelargonium graveolens plant endophytic fungus Colletotrichum sp. used for the synthesis of gold nanoparticles (Shankar et al. 2003). The silver nanoparticles were also synthesized extracellularly by the silver-tolerant yeast strain MKY3 (Kowshik et al. 2003), the fungi Aspergillus fumigatus (Bhainsa and D'Souza 2006), Penicillium sp. (Sadowski et al. 2008), Cladosporium cladosporioides (Balaji et al. 2009), Penicillium fellutanum (Kathiresan et al. 2009), Alternaria alternate (Gajbhiye et al. 2009), Phoma glomerata (Birla et al. 2009), Trichoderma viride (Fayaz et al. 2010), Coriolus versicolor (Sanghi and Verma 2009) and Fusarium solani (Ingle et al. 2009). Recently Penicillium rugulosum and Hormoconis resinae (MTCC 368) have been identified as an exciting candidates for the synthesis of gold nanoparticles extracellularly (Mishra et al. 2012; Mishra et al. 2010) and gold triangular nanoprisms using $T$. asperellum (Mukherjee et al. 2012). Although the area concerning the use of microorganism in synthetic nanomaterials is limited, it is in great progress from the past few years.

In this present study, the fungus $F$. solani was used to synthesize gold nanoparticles. The fungal culture filtrate was used to develop an extracellular process for the synthesis of gold nanoparticles. Gold nanoparticles were observed within $24 \mathrm{~h}$ after $\mathrm{HAuCl}_{4}$-solution was added to the culture filtrate. To our knowledge, this is the first report for the synthesis of gold nanoparticles using $F$. solani.

\section{Materials and methods}

\section{Chemical}

(Chloroauric acid) Hydrogen tetrachloroaurate (III) trihydrate, $\left[\mathrm{HAuCl}_{4} \cdot 3 \mathrm{H}_{2} \mathrm{O}(99.9 \%)\right]$ from Alfa Aesar, was used as received. All other reagents were of analytical grade. Unless otherwise stated, double distilled water was used in all of the experiments.

\section{Identification of fungi}

The F. solani cultures were collected from $\mathrm{PG}$ and Research Department of Plant Biology and Plant Biotechnology, Ramakrishna Mission Vivekananda College, Chennai-4. The identified fungi $F$. solani have small size of micro conidia and macro conidia (Fig. 1) characterized using Confocal laser scanning microscopy (CLSM-710, Carl Zeiss Germany).

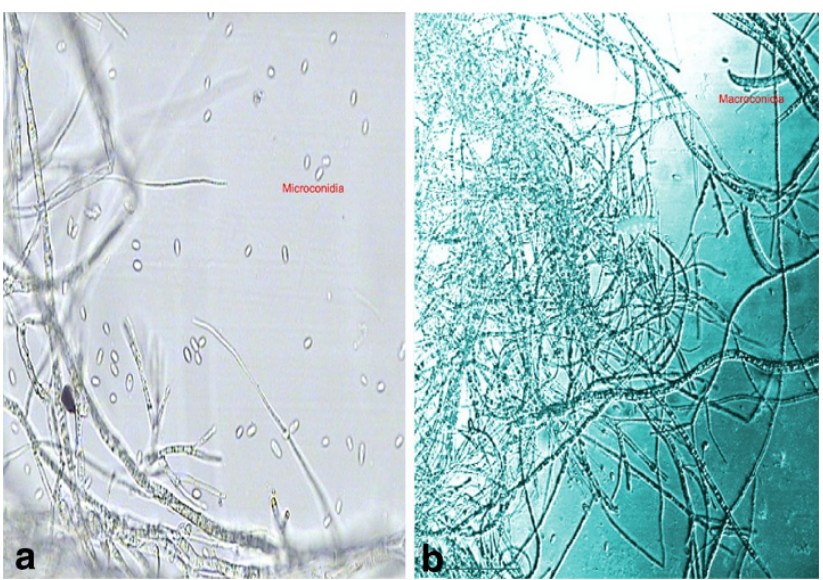

Fig. 1 a Fusarium solani microconidia; b macroconidia

Inoculation

Fusarium solani hyphae are aseptically inoculated in the Czapek-Dox-Broth (CDB) medium containing $30 \mathrm{~g}$ Sucrose, $3 \mathrm{~g}$ Sodium nitrate, $1 \mathrm{~g}$ Dipotassium hydrogen phosphate, $0.5 \mathrm{~g}$ Magnesium sulfate and $0.01 \mathrm{~g}$ Ferrous sulfate, $\mathrm{pH}$ was adjusted to 6.5 with $0.1 \mathrm{~N}$ of $\mathrm{NaOH}$ or $0.1 \mathrm{~N}$ of $\mathrm{HCl}$ before autoclave at $121{ }^{\circ} \mathrm{C}$ and $15 \mathrm{lb}$ for $20 \mathrm{~min}$.

Synthesis of gold nanoparticles

Fusarium solani has grown aseptically in Czapek-DoxBroth (CDB) medium. The conical flask containing medium was incubated at $30{ }^{\circ} \mathrm{C}$ and agitated at $180 \mathrm{rpm}$ for $72 \mathrm{~h}$. After the incubation, the fungal filtrate was obtained by centrifugation at $7,500 \mathrm{rpm}$ for $10 \mathrm{~min}$. The fungal culture medium filtered through Whatman filter paper No.1 and $\mathrm{pH}$ of the collected filtrate was adjusted to 8.5 using $0.1 \mathrm{~N} \mathrm{NaOH}$ or $0.1 \mathrm{~N} \mathrm{HCl}$. To synthesize gold nanoparticles $10 \mathrm{ml}$ of $\mathrm{HAuCl}_{4}$ solution (Fig. 2a) was added drop wise to $90 \mathrm{ml}$ of the culture filtrate (Fig. 2b) with a final concentration $100 \mathrm{ml}$ of $250 \mathrm{mg} / \mathrm{L} \mathrm{HAuCl}{ }_{4}$ solution in an Erlenmeyer flask incubated at $30{ }^{\circ} \mathrm{C}$ and agitated at $180 \mathrm{rpm}$ for $24 \mathrm{~h}$. The accumulation and reduction of gold nanoparticles were observed through the turning of the color of the transparent liquid filtration to purple or pink, which indicates the formation of the gold nanoparticles (Fig. 2c).

Characterization of gold nanoparticles

The biosynthesis of gold nanoparticles was monitored periodically by optical measurements. The liquid sample was scanned by UV-vis spectra for a wavelength range of $350-800 \mathrm{~nm}$. The measurements were carried out on 


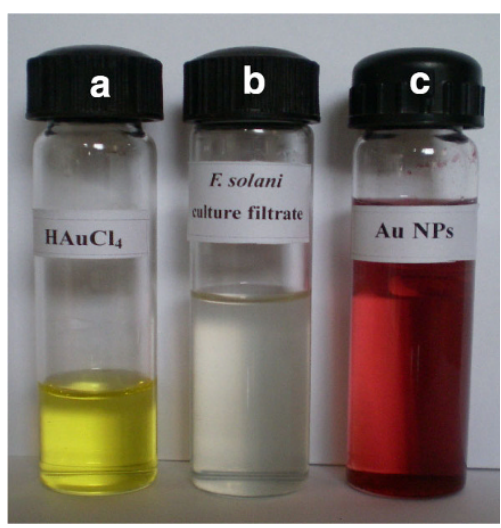

Fig. $2 a \mathrm{HAuCl}_{4}$ solution $(250 \mathrm{mg} / \mathrm{L}), b$ fungal culture filtrate, $c$ 24-h reduction of $\mathrm{HAuCl}_{4}$ added in fungal cultured filtrate

Shimadzu spectrophotometer (Model UV-1800) operating at a resolution of $1 \mathrm{~nm}$. Further, Fourier transform infrared spectroscopy (FTIR) analysis for liquid gold nanoparticles was carried out for the range of $400-4,000 \mathrm{~cm}^{-1}$. The $\mathrm{Au}$ NPs were subjected to X-ray diffraction analysis for the crystallographic structural analysis. The nano-crystallite domain size was calculated from the width of the XDR peaks using Scherrer formula $D=0.9 \lambda / \beta \cos \theta$ (Krishnaraj et al. 2012). X-ray diffraction (XRD) analysis for a thin film sample was prepared on a glass slide $(1 \mathrm{~cm} \times 1 \mathrm{~cm})$ by dropping $100 \mu \mathrm{l}$ of the sample on the slide, and allowed to dry for $30 \mathrm{~min}$, then XRD pattern was recorded using $\mathrm{Cu}$ $\mathrm{K} \alpha$ radiation $(\lambda=1.54060 \AA)$ with nickel monochromator in the range of $2 \theta$ from $10^{\circ}$ to $80^{\circ}$. AFM analysis for a thin film of the sample was prepared on a glass slide $(1 \mathrm{~cm} \times 1 \mathrm{~cm})$ by dropping $100 \mu \mathrm{l}$ of the sample on the slide, and allowed to dry for $30 \mathrm{~min}$. The slides were then scanned with AFM (APE Research-model no: A100SGS). The AFM characterization was carried out in ambient temperature in non-contact mode using silicon nitrite tips with varying resonance frequencies. TEM measurements were carried out to bring out the morphology of the biosynthesized nanoparticles in terms of size and shape. Samples for TEM analysis were prepared by drop coating the nanoparticle solutions on carbon-coated copper grids at room temperature. The excess nanoparticles solution was removed with filter paper. The copper grid was finally dried at room temperature and was subjected to TEM analysis by the instrument Tecnai F20 model operated at an accelerating voltage of $200 \mathrm{kV}$.

\section{Results and discussion}

Biosynthesis of gold nanoparticles using $F$. solani culture filtrate as reducing agent was observed around $24 \mathrm{~h}$. The color of the solution was changed from yellow to dark red which indicates the formation of the Au NPs.

UV-vis spectroscopy

UV-vis absorption spectroscopy was used to measure the absorbance of gold nanoparticles in different intervals such as $1 \mathrm{~min}, 1,12$, and $24 \mathrm{~h}$. The UV-vis spectra illustrated that there is no evidence of an absorption peak in the region of 350-800 nm for the culture filtrated from $F$. solani and $\mathrm{HAuCl}_{4}$ solution. After the $\mathrm{HAuCl}_{4}$ addition with fungus filtration, a well-defined absorption peak at $527 \mathrm{~nm}$ appears in Fig. 3 that corresponds to the wavelength of the surface plasmon resonance of gold nanoparticles (Mukherjee et al. 2002; Mulvaney 1996). Various reports have established that the resonance peak of gold nanoparticles appears around this region (Link and El-Sayed 2000; Nair and Pradeep 2002; Inbakandan et al. 2010). The sharp absorption peak at $527 \mathrm{~nm}$ indicates the presence of gold nanoparticles in the solution.

\section{Fourier transform infrared spectroscopy}

FTIR measurements were carried out to identify the possible biomolecules responsible for the reduction of the $\mathrm{Au}^{+}$ions and capping of the bioreduced gold nanoparticles synthesized by fungal filtrate. Representative spectra of obtained nanoparticles manifests absorption peaks located at about 3,$426 ; 2,077 ; 1,637 ; 1,112$ and $676 \mathrm{~cm}^{-1}$ in the region $400-4,000 \mathrm{~cm}^{-1}$. The FTIR spectra revealed the presence of different functional groups such as free $\mathrm{NH}_{2}$-stretching, C-N stretching, NH-bending, C-O stretching and $\mathrm{Cl}$-stretching. Curve of biosynthesized gold nanoparticles using $F$. solani extract resulted a strong

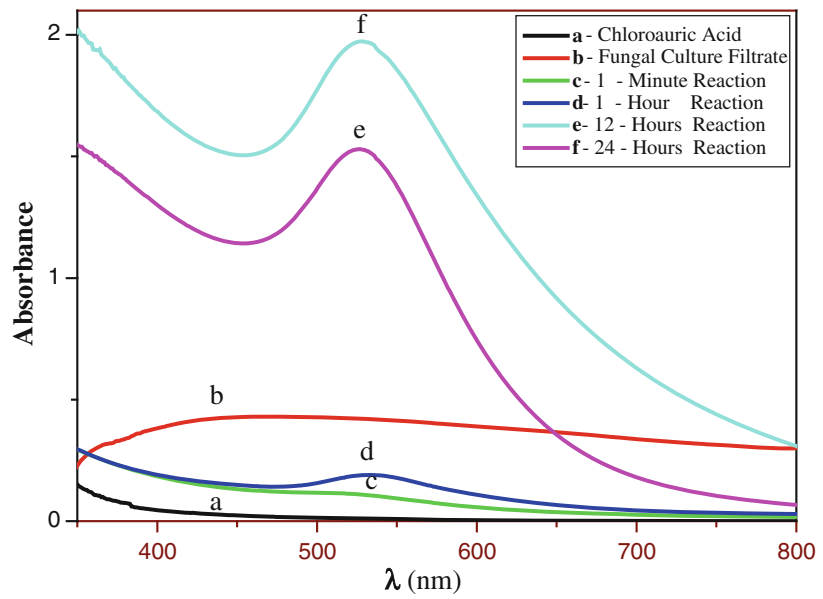

Fig. 3 UV-visible spectrum of nanoparticles at the different timing reaction is indicated next to the respective curves with the extract of $F$. solani and aqueous solution of $250 \mathrm{mg} / \mathrm{L} \mathrm{HAuCl}_{4}(527 \mathrm{~nm})$ 
Fig. 4 FTIR-Spectra recorded from: $a$ F. solani cultural filtrate; $b \mathrm{HAuCl}_{4}$ solution $(250 \mathrm{mg} / \mathrm{L})+F$. solani cultural filtrate using synthesis of gold nanoparticles

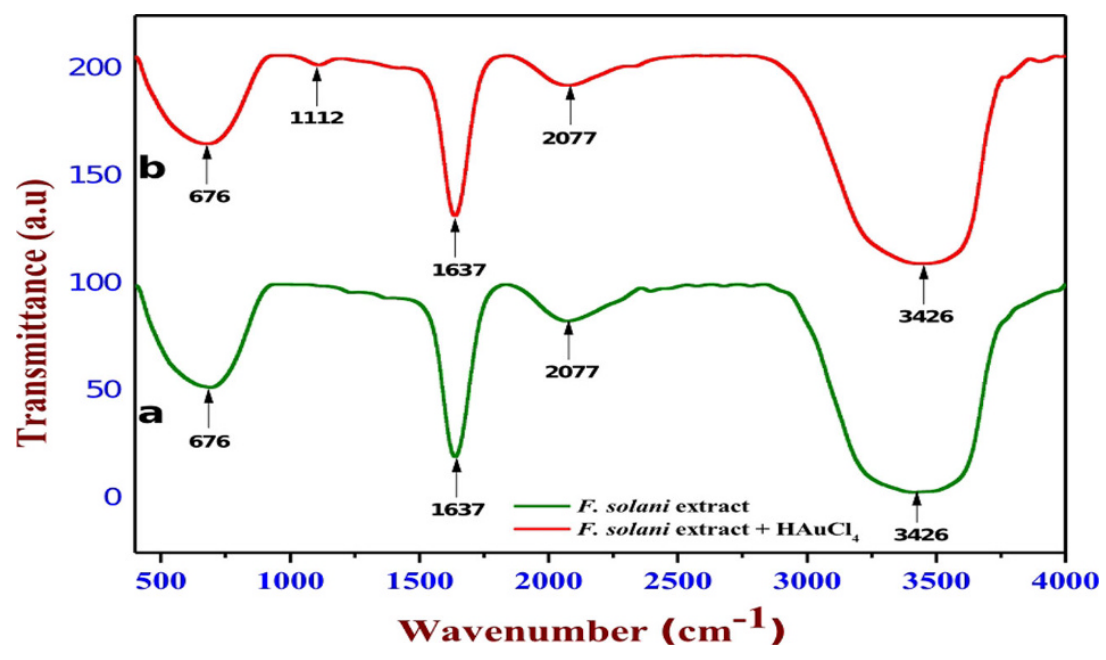

band at $3,426 \mathrm{~cm}^{-1}$ corresponding to $\mathrm{N}-\mathrm{H}$ stretching vibration of primary amines, the band at $2,077 \mathrm{~cm}^{-1}$ corresponding to $\mathrm{C}-\mathrm{N}$ stretching of any $\mathrm{R}-\mathrm{N}=\mathrm{C}=\mathrm{S}$ (Inbakandan et al. 2010), the medium band at $1,638 \mathrm{~cm}^{-1}$ corresponding to similar conjugation effects to $\mathrm{N}-\mathrm{H}$ bending frequency, the low band $676 \mathrm{~cm}^{-1}$ corresponding to $\mathrm{Cl}$ stretching. The heterocyclic ring with nitrogenderived compounds like alkaloids and protein are present in the fungal extract and are the capping ligands for the synthesized gold nanoparticles. FTIR spectra of the culture filtrate of $F$. solani (Fig. 4a) solution show peaks at 3,$426 ; 2,077 ; 1,637$ and $676 \mathrm{~cm}^{-1}$. The addition of $250 \mathrm{mg} / \mathrm{L}$ chloroauric acid in fungal culture for after $24 \mathrm{~h}$ to took out the FTIR result. The new strong band exhibited at $1,112 \mathrm{~cm}^{-1}$ assigned to $\mathrm{C}-\mathrm{O}$ stretching. This peak may be raised due to the reduction of $\mathrm{HAuCl}_{4}$ to $\mathrm{Au}$ nanoparticles (Fig. 4b).

\section{X-ray diffraction pattern}

The XRD patterns obtained for biogenic gold nanoparticles using $F$. solani extract are shown in Fig. 5. XRD analysis showed three distinct diffraction peaks at $38.26^{\circ}, 44.48^{\circ}$ and $66.29^{\circ}$, which can be indexed with the planes (111), (200) and (220) for the cubic face centered gold followed by a small peak at $77.35^{\circ}$ indexed with (311) plane. A number of Bragg reflections corresponding to the lattice planes are observed which may be indexed based on the face-center-cubic (fcc) gold and the values are matched with standard database values (JCPDS No. 04-0784). The XRD pattern thus clearly shows that the gold nanoparticles formed by the reduction of $\mathrm{Au}^{+}$ions by the extract of fungal culture filtrate are crystalline in nature. The similar result was found in XRD patten for intra and extra cellular biosynthesis of gold nanoparticles using Penicillium sp (Liangwei et al. 2011).

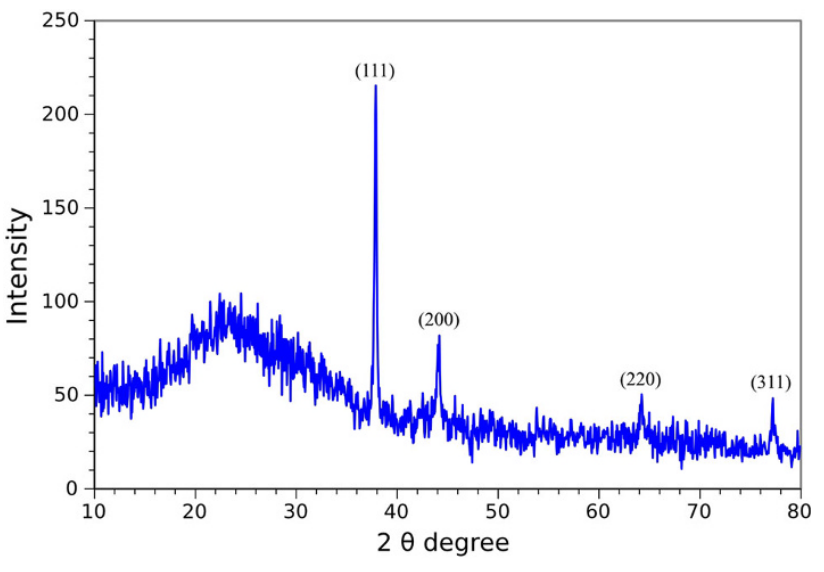

Fig. 5 XRD-Pattern of gold nanoparticles synthesize by treating the extract of $F$. solani with $\mathrm{HAuCl}_{4}$ aqueous solution

Atomic force microscopy and transmission electron micrographs

Surface morphology of the formulated gold nanoparticles was studied by AFM as shown in 2D image (Fig. 6a). The AFM 3D image (Fig. 6b) clearly indicated that, the formulated Au nanoparticles possess uniform spherical shape with the size of $41 \mathrm{~nm}$. The result obtained from the TEM-transmission electron microscopy study showed a very clear indication regarding the shape and size of the nanoparticles. The gold nanoparticles formed were predominantly monodisperse with diameter ranging from 20 to $50 \mathrm{~nm}$ (Fig. 7a). On careful observations of various magnifications of TEM images of gold nanoparticles, it is noted that the particles are of uniform size around $20 \mathrm{~nm}$ (Fig. 7b). Also gold nanoparticles have an inclination of forming thin plannar structures than spherical structures. Figure 7c shows the selected area electron diffraction (SAED) pattern obtained from gold nanoparticles. The Scherrer ring pattern characteristics of face centered cubic 
Fig. 6 a AFM-2D-images and b 3D-images of Au NPs synthesized by $F$. solani

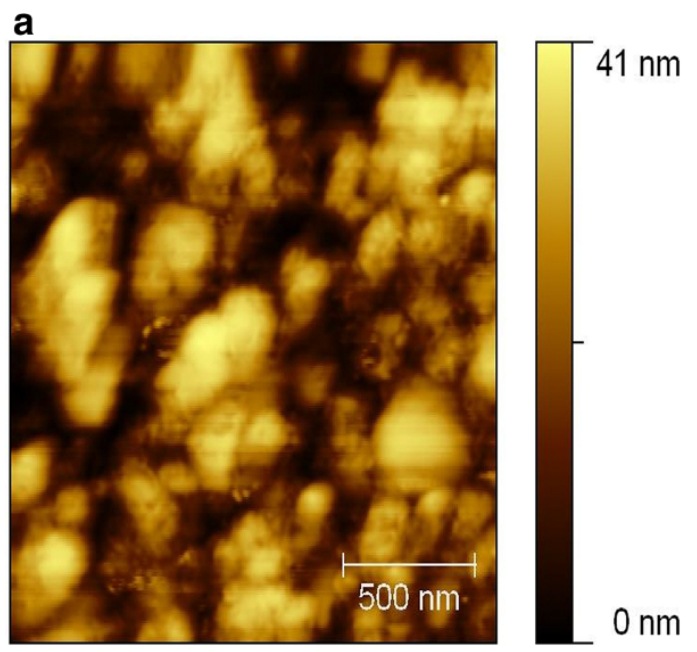

b

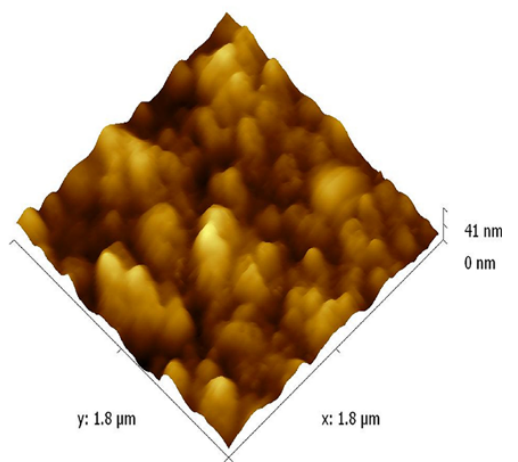

$0 \mathrm{~nm}$
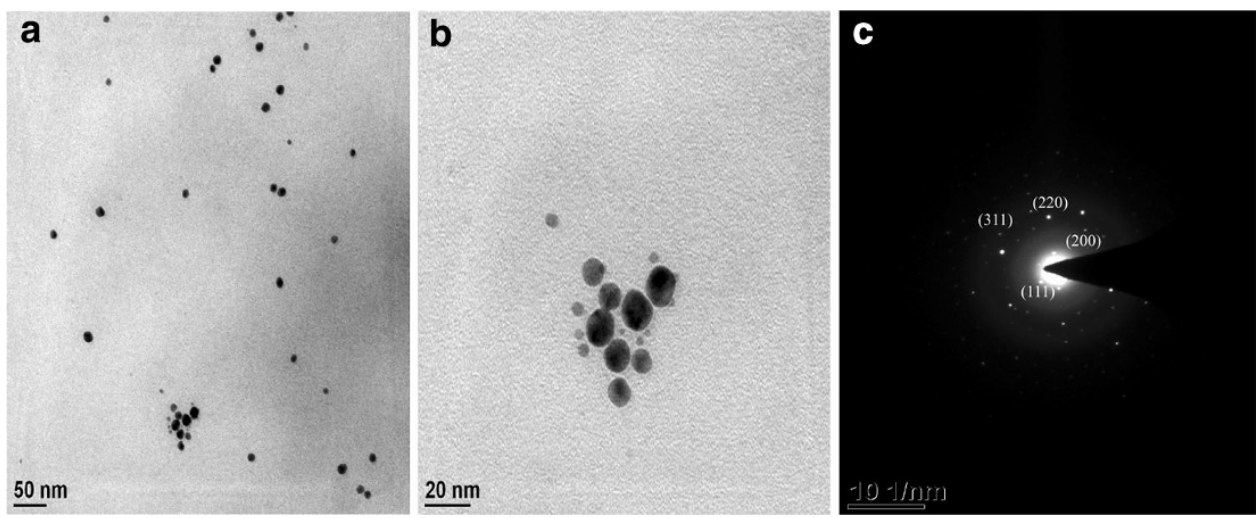

Fig. 7 TEM images of gold nanoparticles formed by reduction of $\mathrm{Au}^{+}$ions using the extract of $F$. solani. a $50 \mathrm{~nm}$ scale, b $20 \mathrm{~nm}$ scale, c TEM image of selected area diffraction pattern (fcc) for gold is clearly observed, showing that the structures seen in TEM images are nanocrystalline in nature.

\section{Conclusion}

The present investigation indicates the extracellular synthesis of gold nanoparticles from $F$. solani culture filtrate. Synthesized gold nanoparticles were characterized by UVvis, FTIR, XRD, AFM, and TEM analysis. TEM results revealed that the gold nanoparticles are highly stable in the diameter range between 20 and $50 \mathrm{~nm}$. This simple biosynthesis procedure for the synthesis of gold nanoparticles has several advantages such as cost-effectiveness, bio compatibility for biomedical, pharmaceutical applications and large-scale commercial production. These fungal extracellular compounds can be extended for the synthesis of other metal and metal oxide nanoparticles.

Acknowledgments We wish to thank Dr. S. Kumaresan, R.K.M.V. College, Chennai for his extensive help in the identification of fungi Fusarium solani. We sincerely thank School of Physics Alagappa University, Karaikudi, for providing XRD instrumental facilities and also thank to the Department of Animal Health and Management, for the CLSM instrumental facilities.
Open Access This article is distributed under the terms of the Creative Commons Attribution License which permits any use, distribution, and reproduction in any medium, provided the original author(s) and the source are credited.

\section{References}

Ahmad A, Senapati S, Khan MI, Kumar R, Sastry M (2003a) Extracellular biosynthesis of monodisperse gold nanoparticles by a novel extremophilic actinomycete, Thermomonospora sp. Langmuir 19:3550-3553. doi:10.1021/la0267721

Ahmad A, Mukherjee P, Senapati S, Mandal D, Khan MI, Kumar R, Sastry M (2003b) Extracellular biosynthesis of silver nanoparticles using the fungus Fusarium oxysporum. Colloids Surf B Biointerfaces 28:313-318. doi:10.1016/S0927-7765(02)00174-1

Balaji DS, Basavaraja S, Deshpande R, Mahesh DB, Prabhakar BK, Venkataraman A (2009) Extracellular biosynthesis of functionalized silver nanoparticles by stains of Cladosporium cladosporioides fungus. Colloids Surf B Biointerfaces 68:88-92. doi: 10.1016/j.colsurfb.2008.09.022

Bhainsa KC, D’Souza SF (2006) Extracellular biosynthesis of silver nanoparticles using the fungus Aspergillus fumigatus. Colloids Surf B Biointerfaces 47:160-164. doi:10.1016/j.colsurfb.2005.11.026

Birla SS, Tiwari VV, Gade AK, Ingle AP, Yadav AP, Rai MK (2009) Fabrication of silver nanoparticles by Phoma glomerata and its combined effect against Escherichia coli, Pseudomonas aeruginosa and Staphylococcus aureus. Lett Appl Microbiol 48:173-179. doi:10.1111/j.1472-765X.2008.02510.x 
Brayner R, Barberousse H, Hemadi M, Djedjat C, Yepremian C (2007) Cyanobacteria as bioreactors for the synthesis of $\mathrm{Au}, \mathrm{Ag}$, $\mathrm{Pd}$, and Pt nanoparticles via an enzyme-mediated route. Nanosci Nanotechnol 7:2696-2708. doi:10.1166/jnn.2007.600

Castro-Longoria E, Vilchis-Nestor AR, Avalos-Borja M (2011) Biosynthesis of silver, gold and bimetallic nanoparticles using the filamentous fungus Neurospora crassa. Colloids Surf B Biointerfaces 83:42-48. doi:10.1016/j.colsurfb.2010.10.035

Chandra PS, Chaudhary M, Pasricha R, Ahmad A, Sastry M (2006) Synthesis of gold nanotriangles and silver nanoparticles using Aloe vera plant extract. Biotechnol Prog 22:577-583. doi: 10.1021/bp0501423

Dubertret B, Skourides P, Norris DJ, Noireaux V, Brivanlou AH, Libchaber A (2002) In vivo imaging of quantum dots encapsulated in phospholipid micelles. Science 298:1759-1762

Duran N, Marcato PD, Alves OL, Souza GI, Esposito E (2005) Mechanistic aspects of biosynthesis of silver nanoparticles by several Fusarium oxysporum strains. Nanobiotech 3:8. doi: 10.1186/1477-3155-3-8

Fayaz AM, Balaji K, Kalaichelvan PT, Venkatesan R (2010) Biogenic synthesis of silver nanoparticles and their synergistic effect with antibiotics: a study against gram-positive and gram-negative bacteria. Nanomedicine NBM 6:103-109. doi:10.1016/j.nano. 2009.04.006

Gajbhiye M, Kesharwani J, Ingle A, Gade A, Rai M (2009) Fungusmediated synthesis of silver nanoparticles and their activity against pathogenic fungi in combination with fluconazole. Nanomedicine NBM 5:382-386. doi:10.1016/j.nano.2009.06.005

Gericke M, Pinches A (2006) Microbial production of gold nanoparticles. Gold Bull 39:22-28. doi:10.1007/BF03215529

Inbakandan D, Venkatesan R, Ajmal Khan S (2010) Biosynthesis of gold nanoparticles utilizing marine sponge Acanthella elongata (Dendy 1905). Colloids Surf B Biointerfaces 81:634-639. doi: 10.1016/j.colsurfb.2010.08.016

Ingle A, Rai M, Gade A, Bawaskar M (2009) Fusarium solani: a novel biological agent for the extracellular synthesis of silver nanoparticles. Nanopart Res 11:2079-2085. doi:10.1007/s11051008-9573-y

Kamat PV (2002) Photophysical, photochemical and photocatalytic aspects of metal nanoparticles. J Phys Chem B Phys Chem B 106:7729-7744. doi:10.1021/jp0209289

Kathiresan K, Manivannan S, Nabeel MA, Dhivya B (2009) Studies on silver nanoparticles synthesized by a marine fungus, Penicillium fellutanum isolated from coastal mangrove sediment. Colloids Surf B Biointerfaces 71:133-137. doi:10.1016/j.colsurfb. 2009.01.016

Kim YC, Park NC, Shin JS, Lee SR, Lee YJ, Moon DJ (2003) Partial oxidation of ethylene to ethylene oxide over nanosized $\mathrm{Ag} /$ alpha- $\mathrm{Al}_{2} \mathrm{O}_{3}$. Catal Today 87:153-162. doi:10.1016/j.cattod. 2003.09.012

Kowshik M, Ashtaputre S, Kharrazi S, Vogel W, Urban J, Kulkarni SK, Paknikar KM (2003) Extracellular synthesis of silver nanoparticles by a silver tolerant yeast strain MKY3. Nanotechnology 14:95-100. doi:10.1088/0957-4484/14//1/321

Krishnaraj C, Ramachandran R, Mohan K, Kalaichelvan PT (2012) Optimization for rapid synthesis of silver nanoparticles and its effect on phytopathogenic fungi. Spectrochim Acta A Mol Biomol Spectrosc 93:95-99. doi:10.1016/j.saa.2012.03.002

Liangwei D, Liang X, Jia-Xun F (2011) Rapid extra-intracellular biosynthesis of gold nanoparticles by the fungus Penicillium sp. Nanopart Res 13:921-930. doi:10.1007/s11051-010-0165-2

Link S, El-Sayed MA (2000) Shape and size dependence of radiative, non-radiative and photothermal properties of gold nanocrystals. Int Rev Phys Chem 19:409-453

Mishra AN, Bhadauria S, Gaur MS, Pasricha R (2010) Extracellular microbial synthesis of gold nanoparticles using fungus
Hormoconis resinae. Metals Mater Soc 62:45-48. doi:10.1007/ s11837-010-0168-6

Mishra A, Tripathy SK, Yun SI (2012) Fungus mediated synthesis of gold nanoparticles and their conjugation with genomic DNA isolated from Escherichia coli and Staphylococcus aureus. Process Biochem 47:701-711. doi:10.1016/j.procbio.2012.01.017

Mukherjee P, Ahmad A, Mandal D, Senapati S, Sainkar SR, Khan MI, Ramani R, Parischa R, Ajayakumar PV, Alam M, Sastry M, Kumar R (2001a) Bioreduction of $\mathrm{AuCl}_{4}{ }^{-}$ions by the fungus, Verticillium sp. and surface trapping of the gold nanoparticles formed. Angew Chem Int Ed 40:3585-3588. doi:10.1002/15213773(20011001)40:19<3585:AID-ANIE3585>3.0.CO;2-K

Mukherjee P, Ahmad A, Mandal D, Senapati S, Sainkar SR, Khan MI, Parishcha R, Ajayakumar PV, Alam M, Kumar R, Sastry M (2001b) Fungus-mediated synthesis of silver nanoparticles and their immobilization in the mycelial matrix: a novel biological approach to nanoparticle synthesis. Nano Lett 1:515-519. doi: $10.1021 / \mathrm{n} 10155274$

Mukherjee P, Senapati S, Mandal D, Ahmad A, Khan MI, Kumar R, Sastry M (2002) Extracellular synthesis of gold nanoparticles by the fungus Fusarium oxysporum. ChemBioChem 3:461-463. doi: 10.1002/1439-7633(20020503)3:5<461:AID-CBIC461>3.0.CO; $2-\mathrm{X}$

Mukherjee P, Roy M, Mandal BP, Choudhury S, Tewari R, Tyagi AK, Kale SP (2012) Synthesis of uniform gold nanoparticles using non-pathogenic bio-control agent: evolution of morphology from nano-spheres to triangular nanoprisms. Colloid Interface Sci 367:148-152. doi:10.1016/j.jcis.2011.08.085

Mulvaney P (1996) Surface plasmon spectroscopy of nanosized metal particles. Langmuir 12:788-800. doi:10.1021/la9502711

Nair B, Pradeep T (2002) Coalescence of nanoclusters and formation of submicron crystallites assisted by Lactobacillus strains. Cryst Growth Des 2:293-298

Parak WJ, Boudreau R, Gros ML, Gerion D, Zanchet D, Micheel CM, Williams SC, Alivisatos AP, Larabell C (2002) Cell motility and metastatic potential studies based on quantum dot imaging of phagokinetic tracks. Adv Mater 14:882-885. doi:10.1002/15214095(20020618)14:12<882:AID-ADMA882>3.0.CO;2-Y

Sadowski Z, Maliszewska IH, Grochowalska B, Polowczyk I, Kozlecki T (2008) Synthesis of silver nanoparticles using microorganisms. Mater Sci Pol 26:419-424

Sanghi R, Verma P (2009) Biomimetic synthesis and characterisation of protein capped silver nanoparticles. Bioresour Technol 100:501-504. doi:10.1016/j.biortech.2008.05.048

Shankar SS, Ahmad A, Parsricha R, Sastry M (2003) Bioreduction of chloroaurate ions by geranium leaves and its endophytic fungus yields gold nanoparticles of different shapes. Mater Chem 13:1822-1826. doi:10.1039/B303808B

Shankar SS, Rai A, Ahmad A, Sastry M (2004) Rapid synthesis of $\mathrm{Au}, \mathrm{Ag}$, and bimetallic Au core-Ag shell nanoparticles using Neem (Azadirachta indica) leaf broth. Colloid Inter Sci 275:496-502. doi:10.1016/j.jcis.2004.03.003

Syed A, Ahmad A (2012) Extracellular biosynthesis of platinum nanoparticles using the fungus Fusarium oxysporum. Colloids Surf B Biointerfaces 97:27-31. doi:10.1016/j.colsurfb. 2012.03.026

Taylor RJ, Fang MM, Nie S (2000) Probing specific sequences on single DNA molecules with bioconjugated fluorescent nanoparticles. Anal Chem 72:1979-1986

Tseng GY, Ellenbogen JC (2001) Toward nanocomputers. Science 294:1293-1294. doi:10.1126/science.1066920

Wu X, Liu H, Liu J, Haley KN, Treadway JA, Larson JP, Ge N, Peale F, Bruchez MP (2003) Immunofluorescent labeling of cancer maker Her2 and other cellular targets with semiconductor quantum dots. Nat Biotechnol 21:41-46. doi:10.1038/nbt0403$452 b$ 